\title{
Impact of Interannual Variability (1979-1986) of Transport and Temperature on Ozone as Computed Using a Two-Dimensional Photochemical Model
}

\author{
Charles H. Jackman, Anne R. Douglass, Sushil Chandra, Richard S. Stolarski \\ JoAN E. Rosenfield, AND JACK A. KAYE \\ Laboratory for Atmospheres, NASA Goddard Space Flight Center, Greenbelt, Maryland
}

ERIC R. NASH

Applied Research Corporation, Landover, Maryland

\begin{abstract}
Eight years of NMC (National Meteorological Center) temperature and SBUV (solar backscattered ultraviolet) ozone data were used to calculate the monthly mean heating rates and residual circulation for use in a two-dimensional photochemical model in order to examine the interannual variability of modeled ozone. Fairly good correlations were found in the interannual behavior of modeled and measured SBUV ozone in the upper stratosphere at middle to low latitudes, where temperature dependent photochemistry is thought to dominate ozone behavior. The calculated total ozone is found to be more sensitive to the interannual residual circulation changes than to the interannual temperature changes. The magnitude of the modeled ozone variability is similar to the observed variability, but the observed and modeled year to year deviations are mostly uncorrelated. The large component of the observed total ozone variability at low latitudes due to the quasi-biennial oscillation (QBO) is not seen in the modeled total ozone, as only a small QBO signal is present in the heating rates, temperatures, and monthly mean residual circulation. Large interannual changes in tropospheric dynamics are believed to influence the interannual variability in the total ozone, especially at middle and high latitudes. Since these tropospheric changes and most of the QBO forcing are not included in our model formulation, it is not surprising that the interannual variability in total ozone is not well represented in our model computations.
\end{abstract}

\section{INTRODUCTION}

A reasonably good qualitative representation of the total ozone seasonal behavior, when compared to total ozone measurements, has been achieved in several two-dimensional (2D) models in recent years, e.g., Pyle [1980], Garcia and Solomon [1983], Ko et al. [1984], Widhopf et al. [1984], Stordal et al. [1985], and Jackman et al. [1989a]; Jackman et al. $[1989 \mathrm{~b}$ ], where the total ozone from several models are presented together; and Yang et al. [1991]. The transportdominated features of measured total ozone such as the northern high-latitude late winter, early spring maximum, and the southern high-latitude off-the-pole maximum in early spring are represented qualitatively in model simulations. These models also simulate the low-latitude solar effects, with the minimum ozone in winter and maximum ozone in summer.

Model ozone profiles differ from measurements in several important respects. In the upper stratosphere, calculated ozone values are lower than measurements; equivalently, for models constrained by observations, calculated ozone loss exceeds production [e.g., Wofsy, 1978; Butler, 1978; Frederick et al., 1978; Johnston and Podolske, 1978; Jackman et al., 1986; Natarajan and Callis, 1989; McElroy and Salawitch, 1989]. In the middle and lower stratosphere, calculated ozone values are generally greater than measured values. In spite of these model-observation ozone profile differences,

Copyright 1991 by the American Geophysical Union.

Paper number 90JD02661.

0148-0227/91/90JD-02661\$05.00 modeled total ozone has been compared carefully to measured total ozone because the measurements of total ozone comprise a long-term, reliable data set.

Two-dimensional residual circulation models (both with fixed circulation and coupled radiation, dynamics, and chemistry) are used to make predictions of future levels of ozone for many decades into the future [World Meteorological Organization (WMO), 1990], which are then used by policy makers in regulations of chlorine-containing source gases. Validation of these $2 \mathrm{D}$ models is important and is derived from many intercomparisons between model results and measurements. Another test of 2D models includes the ability of these models to predict past interannual changes in ozone over a several year time period.

We showed in a previous study [Jackman et al., 1989a] that the total ozone calculated in a $2 \mathrm{D}$ model is sensitive to the vertical winds in the lower stratosphere. We compare in this study the 2D modeled ozone fields (calculated with interannual variability in input temperature and ozone fields) with measured ozone fields. We intend to determine if the use of a yearly changing residual circulation based on SBUV (solar backscatter ultraviolet) ozone and NMC (National Meteorological Center) temperature measurements results in an interannual behavior in ozone which is similar to the observed interannual behavior in ozone.

\section{Temperature ANd Ozone Data (1979-I986)}

The ozone data used in this study consist of monthly values of ozone mixing ratio at a number of pressure levels from 100 mbar to 0.3 mbar measured from the SBUV 


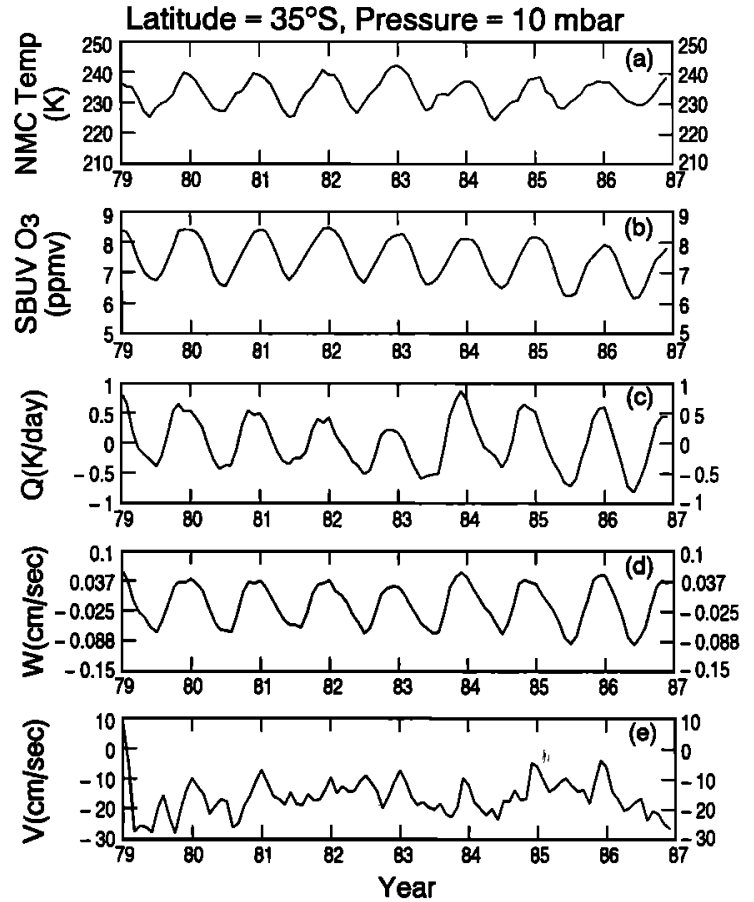

Fig. 1. Interannual changes at $10 \mathrm{mbar}$ and $35^{\circ} \mathrm{S}$ for (a) NMC temperature in degrees Kelvin, (b) SBUV ozone in ppmv, (c) net heating rate $Q$ in degrees Kelvin/d, (d) vertical velocity $w$ in $\mathrm{cm} / \mathrm{s}$, and $(e)$ meridional velocity $v$ in $\mathrm{cm} / \mathrm{s}$.

spectrometer on the Nimbus 7 satellite and the total ozone measured from both the SBUV and total ozone mapping spectrometer (TOMS) instruments on the same satellite. They cover an 8-year time period from January 1979 to December 1986. These data are zonally averaged in $10^{\circ}$ latitude bands and are the current version (version 5) of the processed data as described by Fleig et al. [1990]. The data below 30 mbar are based on climatology and constrained by simultaneous measurements of total ozone. The data above 0.3 mbar are based on climatology.

The NMC temperature covers the same time period and is given at 18 standard pressure levels from 1000 mbar to 0.4 mbar. The temperatures above $10 \mathrm{mbar}$ are based on radiances measured from the vertical temperature profile radiometer (VTPR) on NOAA 5, and the stratospheric sounding unit (SSU) on Tiros $\mathrm{N}$. The temperatures below 10 mbar are based on both the rawinsonde and satellite data.

The satellite-derived temperatures have been adjusted for possible instrument bias based on rocket-measured temperatures as described by Gelman et al. [1986]. This kind of correction is not possible for the SBUV instrument, which has degraded over this 8-year period due to the exposure of the diffuser plates to solar ultraviolet radiation [Watson et al., 1988]. We have therefore carried out our study using both the original data (without removing the linear trends) and the detrended data. The linear trends were removed using a linear regression model at each pressure and latitude surface.

Although some of the ozone change in the upper stratosphere is instrumental, some of the ozone change is real, and total detrending overcompensates for the errors that are solely the result of the degrading instrument. The model studies in which the data with a trend were used were most appropriate when comparing to TOMS total ozone data.
Total ozone is mainly determined by the lower stratospheric part of the ozone profile and the heating rates in this part of the atmosphere are found to be most sensitive to temperature whose measured trend is not in question.

The radiative heating rates were calculated from the ozone and temperature data using a radiative transfer code described by Rosenfield et al. [1987], updated with a new parameterization for ozone infrared absorption [Rosenfield, 1991]. Seasonally averaged latent heating rates from Newell et al. [1974] were added to the radiative heating to derive net diabatic heating rates. Net heating rates and temperatures were then used to compute the monthly residual circulation following Dunkerton [1978].

The 8-year variation in the NMC temperature, SBUV ozone, net heating rate $(Q)$, residual vertical velocity $(w)$, and residual meridional velocity $(v)$ are shown in Figures 1 and 2 at the two levels 10 and 3 mbar for latitude $35^{\circ} \mathrm{S}$. This illustrates the typical interannual changes measured for NMC temperature and SBUV ozone and computed for heating rates, vertical velocities, and meridional velocities. A moderate degree of interannual change is observed in both the measured NMC temperature and SBUV ozone, but the yearly seasonal excursions are clearly larger than the interannual changes. Interannual changes input for the $2 \mathrm{D}$ model include the advection fields ( $w$ and $v$ ) computed with the use of the net heating rate (derived from the measured NMC temperature and SBUV ozone) and the NMC temperature.

\section{Two-Dimensional Model Description}

The residual circulation computed from the 96 months $(8$ years) of ozone and temperature data, as described above, is used in a 2D model [Douglass et al., 1989] for several experiments. The vertical extent of the model is between the
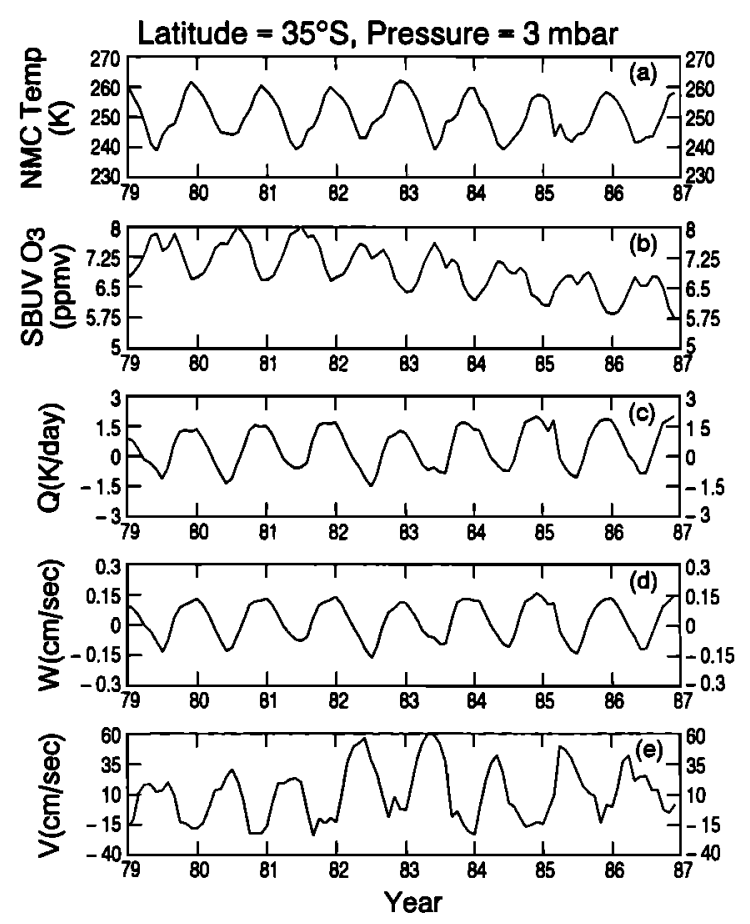

Fig. 2. Interannual changes at $3 \mathrm{mbar}$ and $35^{\circ} \mathrm{S}$ for (a) NMC temperature in degrees Kelvin, (b) SBUV ozone in ppmv, (c) net heating rate $Q$ in degrees Kelvin/d, (d) vertical velocity $w$ in $\mathrm{cm} / \mathrm{s}$, and $(e)$ meridional velocity $v$ in $\mathrm{cm} / \mathrm{s}$. 
ground and 0.23 mbar (approximately $60 \mathrm{~km}$ ), equally spaced in log pressure, with about a 2-km grid spacing and from $85^{\circ} \mathrm{S}$ and $85^{\circ} \mathrm{N}$ with a $10^{\circ}$ grid spacing.

The lower boundary conditions are given in Table 1 for the model background cases used: a simulation of year 1980 with $\sim 2.5 \mathrm{ppbv} \mathrm{Cl}_{x}$ input at the ground. The upper boundary conditions were assumed to be zero flux for all species. Most reaction rates and photodissociation cross sections are taken from DeMore et al. [1987] and presented by Douglass et al. [1989]. Another reaction which was included, but inadvertently left out of Table 2 in Douglass et al. [1989], was $\mathrm{OH}+$ $\mathrm{CH}_{3} \mathrm{CCl}_{3} \rightarrow 3(\mathrm{Cl})+$ Fragments with $k=5.0 \times 10^{-12} \exp$ $(-1800 / T) \mathrm{cm}^{3} \mathrm{~s}^{-1}$ from DeMore et al. [1987].

Eddy diffusion was also specified in the 2D model. The $K_{y y}$ values were taken from Newman et al. [1988] and Jackman et al. [1988] and were determined from a computation of the potential vorticity using seasonally averaged NMC temperature data over the 4-year period from December 1,1978 , to November 30,1982 . The $K_{y z}$ distribution simply relates the mixing on isentropic surfaces to the mixing on pressure surfaces [Jackman et al., 1988]. Both $K_{y y}$ and $K_{y z}$ are seasonally varying but have no interannual change. We fix $K_{z z}$ to $2 \times 10^{3} \mathrm{~cm}^{2} \mathrm{~s}^{-1}$ in the stratosphere with $K_{z z}$ increasing with decreasing altitude in the troposphere to $1 \times 10^{5} \mathrm{~cm}^{2} \mathrm{~s}^{-1}$ at the ground.

The 2D model was run for 20 years to a seasonally repeating steady state for the model background cases. We ran 5 years of 1979 dynamics to a seasonally repeating steady state before starting with 1980,1981 , etc. because the model results for a particular year were somewhat sensitive to the previous years' dynamics (also noted by Schneider et al. [1991]). We likewise focused on the results of the later years (1982-1986) rather than the early years (1979-1981) when comparing our model results to the interannual behavior of ozone. Thirty-three other minor species besides ozone were computed in our model [Douglass et al., 1989], however, ozone is the only species for which global data are available for all 8 years of the model study. Therefore ozone is the only species for which we compare model results with measurements.

We completed a number of model runs, both for the data with a trend and the detrended data. All the model experiments were run for 12 years of model time. In the troposphere, only the temperatures and radiative heating rates

TABLE 1. Lower Boundary Conditions for All Transported Species

\begin{tabular}{|c|c|c|c|}
\hline Species & $\begin{array}{l}\text { Type of Boundary } \\
\text { Condition }\end{array}$ & Unit & $\begin{array}{l}1980 \\
\text { Value }\end{array}$ \\
\hline $\begin{array}{l}\mathrm{N}_{2} \mathrm{O} \\
\mathrm{CH}_{4} \\
\mathrm{CO} \\
\mathrm{H}_{2} \\
\mathrm{CH}_{3} \mathrm{OOH} \\
\mathrm{CH}_{3} \mathrm{Cl} \\
\mathrm{CH}_{3} \mathrm{CCl}_{3} \\
\mathrm{CCl}_{4} \\
\mathrm{CFCl}_{3} \\
\mathrm{CF}_{2} \mathrm{Cl}_{2} \\
\mathrm{O}_{x} \\
\mathrm{HNO}_{3} \\
\mathrm{NO}_{y} \\
\mathrm{Cl}_{x}\end{array}$ & $\begin{array}{l}\text { mixing ratio } \\
\text { mixing ratio } \\
\text { mixing ratio } \\
\text { mixing ratio } \\
\text { flux } \\
\text { mixing ratio } \\
\text { mixing ratio } \\
\text { mixing ratio } \\
\text { mixing ratio } \\
\text { mixing ratio } \\
\text { deposition velocity } \\
\text { mixing ratio } \\
\text { mixing ratio } \\
\text { flux }\end{array}$ & $\begin{array}{l}\text { ppbv } \\
\text { ppmv } \\
\text { ppbv } \\
\text { ppbv } \\
\text { cm }^{-2} \mathrm{~s}^{-1} \\
\text { pptv } \\
\text { pptv } \\
\text { pptv } \\
\text { pptv } \\
\text { pptv } \\
\text { cm s s } \\
\text { pptv } \\
\text { pptv } \\
\mathrm{cm}^{-2} \mathrm{~s}^{-1}\end{array}$ & $\begin{array}{c}300 \\
1.6 \\
100 \\
500 \\
0.0 \\
700 \\
100 \\
100 \\
170 \\
285 \\
0.1 \\
90 \\
100 \\
0.0\end{array}$ \\
\hline
\end{tabular}
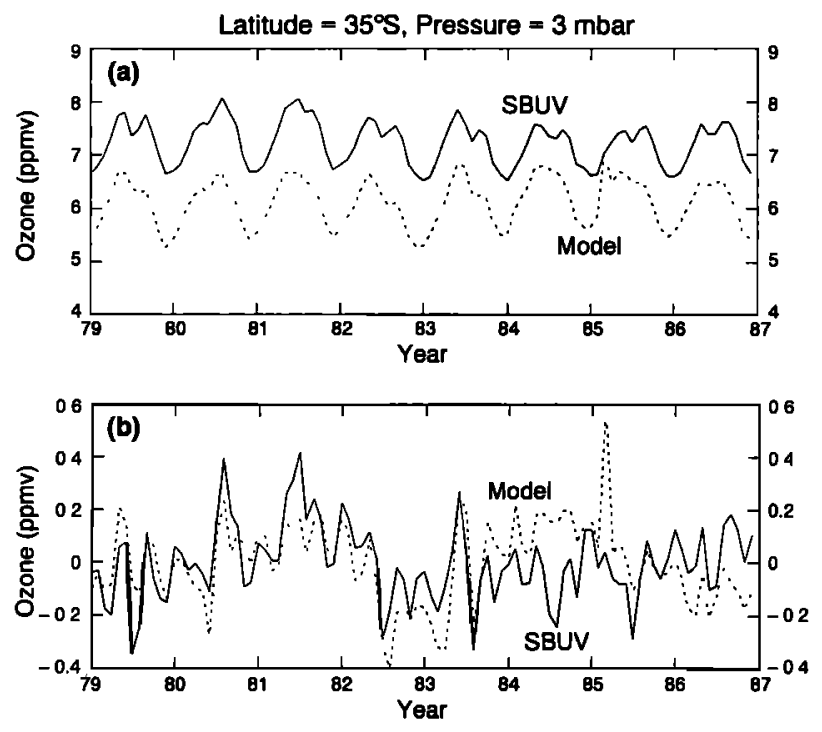

Fig. 3. (a) Ozone (ppmv) at $3 \mathrm{mbar}$ and $35^{\circ} \mathrm{S}$ from detrended SBUV data (solid line) and model experiment using detrended SBUV ozone and NMC temperature data (dashed line). (b) Ozone (ppmv) residual deviations in the model and data after annual and semiannual components are removed.

had interannual variation; the diffusion coefficients, the latent heat, and the tropopause height were all fixed.

Solar cycle ultraviolet (UV) flux variation was not accounted for in any of our computer simulations. Some variation is expected in the background species' abundance because of the solar cycle UV flux variation. We do not include this UV change, so that it is possible to analyze more easily the straightforward influence of interannual dynamics behavior.

\section{Model Simulation Using Detrended Ozone AND TEMPERATURE DATA}

The model results using the detrended data provide the best comparison between model profile ozone and SBUV data, since there is such a large trend in the SBUV data over the 8-year time period. The largest calculated changes in ozone are found in the lower stratosphere/upper troposphere.

In the upper stratosphere, where photochemistry is more important than transport, the model $\mathrm{O}_{3}$ is $15-20 \%$ lower than the SBUV data at $3 \mathrm{mbar}$, but the behaviors are in qualitative agreement. The detrended SBUV data (solid line) and model ozone (dashed line) given in Figure $3 a$ at $3 \mathrm{mbar}$ and $35^{\circ} \mathrm{S}$ exhibit annual and semiannual changes caused by the annual and semiannual temperature swings. The correlation coefficient between model and data in Figure $3 a$ is at a very high value of 0.87 (significant to the $99 \%$ confidence level). We have removed the annual and semiannual components of both model and SBUV ozone and present the residual changes in Figure $3 b$. These smaller residual ozone changes are similar in both the model and SBUV data and are primarily caused by inverse temperature variations associated with the temperature dependence of reactions which destroy odd oxygen. The correlation coefficient for the model and data compared in Figure $3 b$ is at a moderate value of 0.48 (significant to the $99 \%$ confidence level).

The SBUV ozone is best between 30 and 1 mbar; thus we 


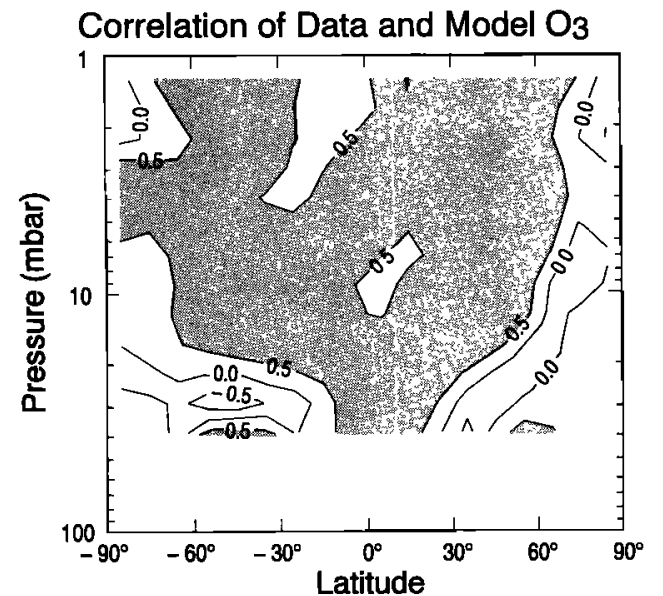

Fig. 4. Correlation coefficient of SBUV ozone data with modeled ozone simulation using detrended SBUV ozone and NMC temperature data for all months together in years 1982-1986. Crosshatched areas indicate values where correlation coefficient is larger than 0.5 . The value for the $95 \%$ confidence levels for the 60 months that are included in this calculation is $\mathbf{0 . 2 1}$.

only show model-measurement comparisons in that region. We computed the correlation coefficient between the data (detrended) and detrended model run for the last 5 years of the run (1982-1986), which is shown in Figure 4. The 95\% confidence level is 0.21 for Figure 4 (which includes 60 months of data). In Figure 4 the seasonal behavior of ozone drives the correlation and a very high level of correlation $(0.5-0.9)$ is achieved in the middle to upper stratosphere and in the middle to low latitudes. The modeled and measured ozone values in the middle to lower parts of the stratosphere are largely uncorrelated. The correlation is reduced when the annual and semiannual cycles are filtered out from both the model and measured ozone values, as illustrated in Figure $3 b$. The correlation in the upper stratosphere which results after filtering out the annual and semiannual cycles is in the range of $0.3-0.6$ compared to values of $0.5-0.9$ shown in Figure 4.

\section{Model Simulation Using Ozone and Temperature Data With the Trend}

We used ozone and temperature with the trend in a model simulation to compare modeled total ozone with data (TOMS). We found that the temperature differences from year to year are the major contributors to the calculated differences in the lower stratospheric heating rates and circulation, in agreement with Schneider et al. [1991]. Before discussing the results of the interannual comparisons in total ozone for the model experiments, we first show a comparison of modeled total ozone with TOMS data. This is illustrated in Figure 5, where both the TOMS data and the modeled total ozone are presented for 1986.

There is qualitative similarity between the model and measurements, but significant difference in detail. The model represents the northern hemisphere high-latitude late winter peak qualitatively, although the model's higher values extend to lower latitudes than indicated in the TOMS data. The low-latitude solar zenith angle effect is observed in both model and data, with higher ozone values observed in both hemispheres during summer and lower ozone values during (a) TOMS Total Ozone (1986)

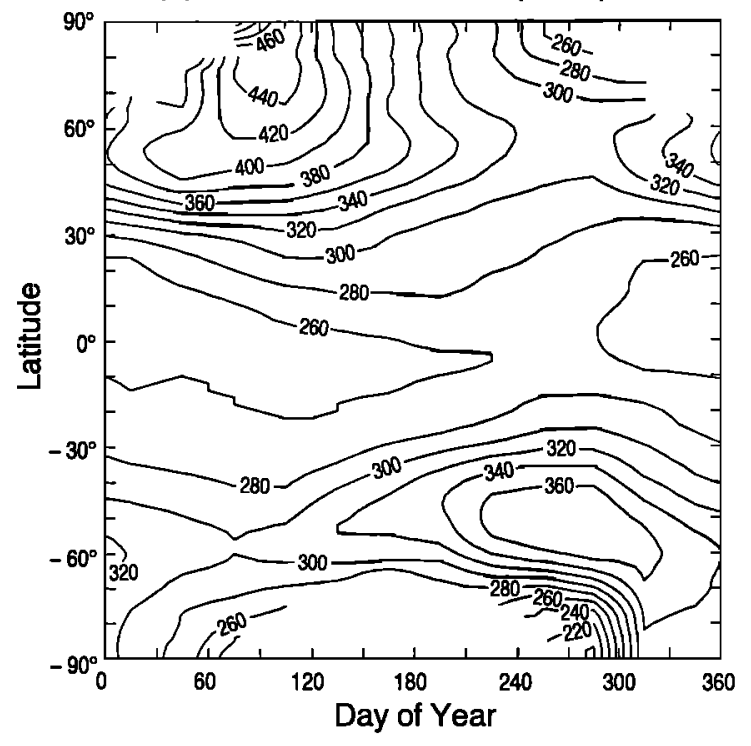

(b) Model Total Ozone (1986)

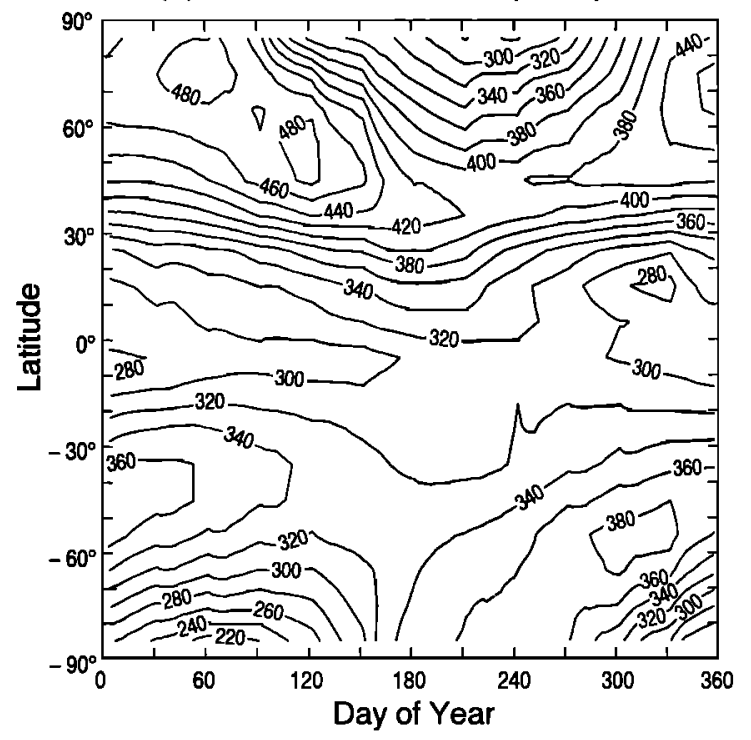

Fig. 5. Total ozone for 1986 in Dobson units from (a) TOMS (total ozone mapping spectrometer) and $(b)$ from model results using SBUV ozone and NMC temperature data including the trend.

winter. A quantitative difference is apparent in the lower latitudes with the model predicting up to 40 Dobson units more ozone than indicated in the data. An off-the-pole southern hemisphere winter maximum occurs in both model and TOMS data; however, the model ozone differs significantly from TOMS at southern high latitudes. Among the factors that probably contribute to this disagreement are the omission of polar heterogeneous chemistry and the errors in the SBUV ozone profiles in the Antarctic region [McPeters et al., 1986]. Rosenfield et al. [1988] show that lower stratospheric heating rates and vertical advection in the Antarctic springtime are very sensitive to ozone amounts and the vertical gradient of the ozone mixing ratio profile.

The ratios of the seasonally averaged total ozone from the TOMS data to the model values are given in Figure 6 as a function of latitude for 1982-1986. There are some absolute 

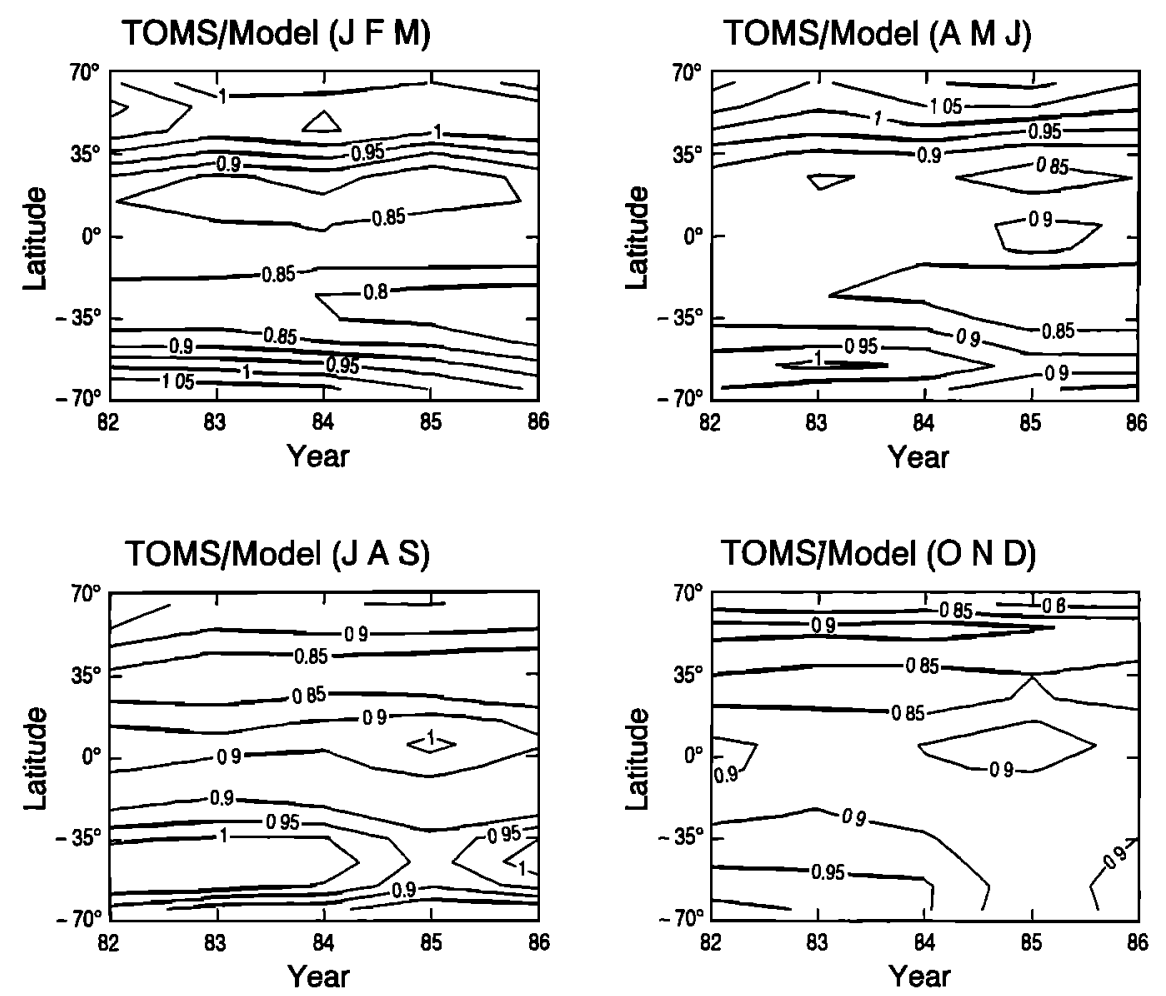

Fig. 6. Total ozone from TOMS divided by the model computed total ozone for January-February-March (J F M), April-May-June (A M J), July-August-September (J A S), and October-November-December (O N D).

differences between the data and model values, indicated by the range of contours from 0.8 to 1.1 . The interannual variations are much different in the model and data, as the contours are much different from the straight lines that would indicate agreement between modeled and observed variability. Although some latitudes and seasons (e.g., OND (October-November-December) northern latitudes) compare more favorably than others (JAS (July-August-September) southern latitudes 1984-1986), the overall comparison is poor and suggests that physical processes important to the observed interannual variability of total ozone are not included in this model.

There are a number of possibilities which could explain the poor comparisons between the interannual behavior in model predictions and measurements. These are (1) the input ozone values are not true measurements below 30 mbar, but rather rely on climatology and the measurement of total ozone, (2) the horizontal eddy diffusion rates vary monthly, but they have no interannual behavior, (3) the QBO is not represented with only the input temperature changes [Gray and Pyle, 1989; Gray and Chipperfield, 1990], and (4) tropospheric interannual changes are not well represented (e.g., the latent heat changes monthly but with no interannual behavior).

Use of climatological ozone rather than measured ozone below 30 mbar is not believed to be very important in the interannual changes under investigation here; below 30 mbar the heating rate changes are influenced mainly by temperature changes [Schneider et al., 1991]. We did complete two other sets of model experiments in order to investigate the sensitivity of our results to interannual heating rate changes, interannual temperature changes, and interannual horizontal eddy diffusion changes.
In the first set of model experiments, we compared three model transport and temperature formulations: (1) the interannual heating rate and temperature changes together were both included (the model base simulation), (2) only the interannual heating rate changes were included, together with a fixed annual cycle of temperature, and (3) only the interannual temperature changes were included, together with a fixed annual cycle of heating rates. We found from these model simulations that the total ozone is more dependent on the heating rate changes than on the temperature changes.

In the second set of model experiments we compared two model calculations: (1) the model base simulation with $K_{y y}$ values from Newman et al. [1988] and Jackman et al. [1988] along with the interannual heating rate and temperature changes; and (2) a model simulation including self-consistent $K_{y y}$ computed from the residual meridional velocity (see section 5 of Jackman et al. [1988]) along with the interannual heating rate and temperature changes. We found that our model results were relatively insensitive to these horizontal eddy diffusion changes. Yang et al. [1990, 1991] indicate that the interannual $K_{y y}$ changes corresponding to interannual transport changes can be computed more exactly than undertaken here. An indication of these interannual $K_{y y}$ changes can be found in Figure 15 of Yang et al. [1990]. These large interannual changes in $K_{y y}$ computed by Yang and coauthors suggest that corresponding large interannual changes in total ozone might be possible from only the interannual $K_{y y}$ variations. The sensitivity of $2 \mathrm{D}$ model results to interannual $K_{y y}$ changes requires further study before a final judgment can be made on the $K_{y y}$ and their significance in determining total ozone amounts.

The QBO forcing and the tropospheric interannual 
changes are two of the largest interannual atmospheric changes which are not well represented in our model computation. There is a clear signal of the quasi-biennial oscillation in the tropical total $\mathrm{O}_{3}$ and zonal wind [see Lait et al., 1989]; no such signal is present in the heating rates and derived vertical winds in that region. Although the tropospheric interannual changes in temperature are included through the NMC data set, the more important interannual variations in the tropopause height, weather systems, and wave actions are not represented in these model computations.

\section{SUMMARY AND CONCLUSIONS}

The seasonally averaged climatological behavior of total ozone is fairly well represented with a $2 \mathrm{D}$ model residual circulation formulation. Such formulations have been previously shown to have a large sensitivity of total ozone to the circulation. We have used 8 years of SBUV ozone data and NMC temperature data to examine the sensitivity of modeled ozone interannual variability to interannual changes in ozone and temperature. The magnitude of the modeled ozone variability is similar to the observed variability, but the observed and modeled year-to-year variations are mostly uncorrelated. Two major problems are apparent: (1) the quasi-biennial oscillation in low-latitude total ozone is not present in the model calculations, and (2) the interannual variability in tropospheric forcing of the stratospheric circulation is not represented and is important in determining the year-to-year variations.

Future work in this type of detailed model-measurement comparison should use a more complete data set for the interannual ozone and temperature behavior, a better representation of the QBO signal, and a better representation of the interannual behavior of the troposphere. Detailed studies of this nature, however, can be of use for certain well-posed problems concentrating on specific areas of the atmosphere.

Acknowledgments. We thank Hans R. Schneider (Atmospheric and Environmental Research, Inc.) for useful comments and criticisms on an earlier version of this manuscript. The authors acknowledge NASA Headquarters Upper Atmosphere Theory and Data Analysis Program for support during the time that this project was undertaken. J. E. R. is a Universities Space Research Association Resident Associate.

\section{REFERENCES}

Butler, D. M., The uncertainty in ozone calculations by a stratospheric photochemistry model, Geophys. Res. Lett., 5, 769-772, 1978.

DeMore, W. B., J. J. Margitan, M. J. Molina, R. T. Watson, D. M. Golden, R. F. Hampson, M. J. Kurylo, C. J. Howard, and A. R. Ravishankara, Chemical kinetics and photochemical data for use in stratospheric modeling, $J P L$ Publ., 87-4l, 1987.

Douglass, A. R., C. H. Jackman, and R. S. Stolarski, Comparison of model results transporting the odd nitrogen family with results transporting separate odd nitrogen species, J. Geophys. Res., 94, 9862-9872, 1989.

Dunkerton, T., On the mean meridional mass motions of the stratosphere and mesosphere, J. Atmos. Sci., 35, 2325-2333, 1978.

Fleig, A. J., R. D. McPeters, P. K. Bhartia, B. M. Schlesinger, R. M. Cebula, K. F. Klenk, S. L. Taylor, and D. F. Heath, Nimbus 7 solar backscatter ultraviolet (SBUV) ozone products user's guide, NASA Ref. Publ., 1234, 1990.

Frederick, J. E., B. W. Guenther, P. B. Hays, and D. F. Heath,
Ozone profiles and chemical loss rates in the tropical stratosphere deduced from backscatter ultraviolet measurements, J. Geophys. Res., 83, 953-958, 1978.

Garcia, R. R., and S. Solomon, A numerical model of the zonally averaged dynamical and chemical structure of the middle atmosphere, J. Geophys. Res., 88, 1379-1400, 1983.

Gelman, M. E., A. J. Miller, K. W. Johnson, and R. M. Nagatani, Detection of long term trends in global stratospheric temperature from NMC analyses derived from NOAA satellite data, $A d v$. Space Res., 6(10), 17-26, 1986.

Gray, L. J., and M. P. Chipperfield, On the interannual variability of trace gases in the middle atmosphere, Geophys. Res. Lett., 17, 933-936, 1990.

Gray, L. J., and J. A. Pyle, A two dimensional model of the quasi-biennial oscillation of ozone, J. Atmos. Sci., 46, 203-220, 1989.

Jackman, C. H., R. S. Stolarski, and J. A. Kaye, Two-dimensional monthly average ozone balance from limb infrared monitor of the stratosphere and stratospheric and mesospheric sounder data, $J$. Geophys. Res., 91, 1103-1116, 1986.

Jackman, C. H., P. A. Newman, P. D. Guthrie, and M. R. Schoeberl, Effect of computed horizontal diffusion coefficients on two-dimensional $\mathrm{N}_{2} \mathrm{O}$ model distributions, J. Geophys. Res., 93, 5213-5219, 1988.

Jackman, C. H., A. R. Douglass, P. D. Guthrie, and R. S. Stolarski, The sensitivity of total ozone and ozone perturbation scenarios in a two-dimensional model due to dynamical inputs, J. Geophys. Res., 94, 9873-9887, 1989a.

Jackman, C. H., R. K. Seals, Jr., and M. J. Prather, Twodimensional intercomparison of stratospheric models, NASA Conf. Publ., 3042, 1989 b.

Johnston, H. S., and J. Podolske, Interpretation of stratospheric photochemistry, Rev. Geophys., 16, 491-519, 1978.

Ko, M. K. W., N. D. Sze, M. Livshits, M. B. McElroy, and J. A. Pyle, The seasonal and latitudinal behavior of trace gases and $\mathrm{O}_{3}$ as simulated by a two-dimensional model of the atmosphere, $J$. Atmos. Sci., 4I, 2381-2408, 1984.

Lait, L. R., M. R. Schoeberl, and P. A. Newman, Quasi-biennial modulation of the Antarctic ozone depletion, J. Geophys. Res., 94, 11,559-11,571, 1989.

McElroy, M. B., and R. J. Salawitch, Changing composition of the global stratosphere, Science, 243, 763-770, 1989.

McPeters, R. D., R. D. Hudson, P. K. Bhartia, and S. L. Taylor, The vertical ozone distribution in the Antarctic ozone minimum measured by SBUV, Geophys. Res. Lett., 13, 1213-1216, 1986.

Natarajan, M., and L. B. Callis, Examination of stratospheric ozone photochemistry in light of recent data, Geophys. Res. Lett., 16, 473-476, 1989.

Newell, R. E., J. W. Kidson, D. G. Vincent, and G. J. Boer, The General Circulation of the Tropical Atmosphere, vol. 2, chap. 7, MIT Press, Cambridge, Mass., 1974.

Newman, P. A., M. R. Schoeberl, R. A. Plumb, and J. E. Rosenfield, Mixing rates calculated from potential vorticity, J. Geophys. Res., 93, 5221-5240, 1988.

Pyle, J. A., A calculation of the possible depletion of ozone by chlorofluorocarbons using a two-dimensional model, Pure Appl. Geophys., 118, 355-377, 1980.

Rosenfield, J. E., A simple parameterization of ozone infrared absorption for atmospheric heating rate calculations, J. Geophys. Res., in press, 1991.

Rosenfield, J. E., M. R. Schoeberl, and M. A. Geller, A computation of the stratospheric diabatic residual circulation using an accurate radiative transfer model, J. Atmos. Sci., 44, 859-876, 1987.

Rosenfield, J. E., M. R. Schoeberl, and P. A. Newman, Antarctic springtime ozone depletion computed from temperature observations, J. Geophys. Res., 93, 3833-3849, 1988.

Schneider, H. R., M. K. W. Ko, C. A. Peterson, and E. R. Nash, Interannual variations of ozone: Interpretation of 4 years of satellite observations of total ozone, J. Geophys. Res., 96, 28892896, 1991.

Stordal, R., I. S. A. Isaksen, and K. Horntveth, A diabatic circulation two-dimensional model with photochemistry: Simulations of ozone and long-lived tracers with surface sources, $J$. Geophys. Res., 90, 5757-5776, 1985.

Watson, R. T., M. J. Prather, and M. J. Kurylo, Present state of 
knowledge of the upper atmosphere 1988: An assessment report, NASA Ref. Publ., 1208, 1988.

Widhopf, G. F., L. Glatt, and E. Ruth, Two-dimensional description of potential perturbations to the ozone layer due to $\mathrm{NO}_{x}$ and $\mathrm{H}_{2} \mathrm{O}$ aircraft emissions, Rep. FAA-EE-84-11, Fed. Aviat. Admin., Washington, D. C., 1984.

Wofsy, S. C., Temporal and latitudinal variations of stratospheric trace gases: A critical comparison between theory and experiment, J. Geophys. Res., 83, 364-378, 1978.

World Meteorological Organization, Scientific assessment of stratospheric ozone: 1989, WMO Rep. 20, Geneva, 1990.

Yang, H., K. K. Tung, and E. Olaguer, Nongeostrophic theory of zonally averaged circulation, II, Eliassen-Palm flux divergence and isentropic mixing coefficient, J. Atmos. Sci., 47, 215-241, 1990.
Yang, H., E. Olaguer, and K. K. Tung, Simulation of the presentday chemical composition of the stratosphere using a coupled 2-D model in isentropic coordinates, J. Atmos. Sci., in press, 1991.

S. Chandra, A. R. Douglass, C. H. Jackman, J. A. Kaye, J. E. Rosenfield, and R. S. Stolarski, Laboratory for Atmospheres, Code 916, NASA Goddard Space Flight Center, Greenbelt, MD 20771.

E. R. Nash, Applied Research Corporation, Landover, MD 20785.

(Received August 6, 1990;

revised December 6, 1990;

accepted December 10, 1990.) 